\title{
Phototherapy Induces an Improvement In Clinical and Biochemical Scores In Rheumatoid Arthritis
}

JM Calderón ${ }^{1}$, GA Huacuz ${ }^{1}$, IG Sánchez, AG Vilchis ${ }^{1}$, HM Zerón ${ }^{1,2}$

\begin{abstract}
Objective: Rheumatoid arthritis is a common autoimmune disease for which there is no known cure. Ultraviolet light can induce immunosuppressive effects. Our main objective was to ascertain whether a complementary treatment with phototherapy improves changes in functional scales in patients with rheumatoid arthritis.

Methods: Seven women with rheumatoid arthritis were enrolled for this study and submitted to phototherapy sessions with a 425 to $650 \mathrm{~nm}$ lamp.

Results: The Karnofsky scale changed from requiring frequent medical care to being capable of normal activity with few symptoms or signs of disease $(p=0.018)$, the RaQol questionnaire decreased abruptly from 29 to zero points $(p=0.018)$, the Steinbrocker Functional Capacity Rating changed from limited to little or none of the duties of usual occupation or self-care to complete ability to carry out all the usual duties without handicaps $(p=0.017)$. The pain was remitted after the treatment period. The acute inflammation variables showed a significant decrease after the indicated sessions, C-reactive protein $(p=0.042)$, erythrocyte sedimentation rate $(p=0.018)$.

Conclusion: The evaluated scales clearly show a benefit with the phototherapy in rheumatoid arthritis patients. Thus, phototherapy seems to be a plausible complementary option to reduce the symptoms in rheumatoid arthritis.
\end{abstract}

Keywords: C-reactive protein, functional scales, phototherapy, rheumatoid arthritis

From: ${ }^{1}$ Maternal-Perinatal Hospital "Mónica Pretelini Sáenz", Health Institute of the State of Mexico and ${ }^{2}$ Asociación Científica Latina (ASCILA) and Ciprés Grupo Médico. Toluca, Mexico.

Correspondence: Dr HM Zerón, Felipe Villanueva sur 1209. Col. Rancho Dolores. 50170. Toluca, Mexico. Telephone: +52-7222194122; fax: +52-7222194122.

E-mail: mezh_74@yahoo.com 


\section{INTRODUCTION}

Rheumatoid arthritis (RA) is a common autoimmune disease for which there is no known cure. A diverse number of biological pathways are altered in patients with RA, which impinge on a wide-variety of cell types, tissue types and organ systems - innate immune cells ( $e g$ dendritic cells, mast cells, neutrophils, platelets), adaptive immune cells (eg B and T-cells), bone, cartilage, synovial fibroblasts, vascular cells, brain, muscle and fat (1). The chronic manifestations of RA are primarily manifested in the synovial tissues, with symptoms of pain, stiffness, swelling, and progressive joint destruction (2).

Drugs used for treatment can be divided into four broad categories: non-steroidal antiinflammatory drugs (NSAIDs), glucocorticoids, disease modifying antirheumatic drugs (DMARDs) and biologic agents. Since 2002, treatment recommendations for RA have suggested an aggressive approach to inhibit the progression of joint damage and other complications that may develop soon after diagnosis (3-5). This aggressive approach includes initiation of DMARDs and biologic agents as soon as possible.

Among complementary alternatives to treat RA we find the use of light. In this respect, the frequency, wavelength and energy of an electromagnetic wave are related to one another with wavelength being inversely proportional to both frequency and energy. The huge spectrum of electromagnetic radiation can therefore be organized conceptually by decreasing wavelength into radio waves, microwaves, terahertz radiation, infrared radiation, visible light, ultraviolet (UV) radiation, X-rays and gamma rays.

Phototherapy is defined as the use of UV radiation in the treatment of skin disease. There are many types of phototherapy including: broadband UVB $(280-320 \mathrm{~nm})$, narrowband UVB (311-313 nm), UVA (340-400 nm), and combination therapy of psoralen plus UVA (PUVA). 
Although UV light can induce strong inflammatory responses in susceptible individuals, under chronic or minimally erythematogenic doses its immunosuppressive effects are dominant. The mechanism of this immunosuppression involves both cellular components and soluble mediators (6). For example, Langerhans cells are very sensitive to UV radiation. These cells express molecules such as: MHC class II, lymphocyte function-associated antigen-3 (LFA-3), intercellular adhesion molecule (ICAM)-1, ICAM-3, B7, CD1a and CD40. Ultraviolet radiation induces these cells to migrate out of the skin to draining lymph nodes (7-8) and there is a dramatic reduction in the previously mentioned markers following UV exposure (9).

Our main objective was to evaluate the changes in functional scales, biochemical and inflammatory variables in RA patients submitted to phototherapy within a range from 425 to 650 $\mathrm{nm}$ (visible light spectrum) and 11.33 Joules $/ \mathrm{cm}^{2}$.

\section{METHODS}

In this descriptive, prospective, longitudinal and quasi-experimental clinical study, women attending the Research Department of the Maternal-Perinatal Hospital "Mónica Pretelini Sáenz" (HMPMPS), Health Institute of the State of Mexico (ISEM), Toluca, State of Mexico, Mexico, who meet the criteria established by the American College of Rheumatology (10) for the diagnosis of RA were included in the study. Patients with previous fractures, chronic diseases that limit the functional capacity, other arthropathies or overlap syndromes were not included.

An essential aspect of the study was the absolute respect to the management, evaluation and subsequent citations instituted by the treating rheumatologist. Only in cases where the patient was not receiving specialized care or that their problem was recently installed and did not have 
opportunity to apply this specialized care, we initiated the pharmacological management in conjunction with phototherapy.

We obtained the general personal data from a medical history; anthropometry, biochemical evaluations and clinical scales to evaluate the RA affection were evaluated weekly.

Anthropometric measures were assessed in the Research Laboratory of the HMPMPS. Body weight was measured in an overnight fasting status without shoes in a minimal clothing state by the use of a digital scale (Seca, Hamburg, Germany) to the nearest $0.1 \mathrm{~kg}$. Height was measured using a non-stretched tape measure to the nearest $0.1 \mathrm{~cm}$. Body mass index (BMI) was calculated as weight in $\mathrm{kg}$ divided by height in meters squared.

We applied the next clinical evaluations: Karnofsky scale, quality of life-rheumatoid arthritis (QOL-RA), rheumatoid arthritis-specific quality of life (RAQoL) instrument, steinbrocker functional capacity rating and the visual analog scale (VAS). Also, we evaluated the next items: spontaneous pain, pressure pain, movement pain and inflammation (flogosis) with the next parameters: 0 (absent), + (light), ++ (moderate), +++ (sever); functional limitation and temperature rise were classified as: 0 (absent), 1 (present); strength (excluding hands) was evaluated as: 1 (normal), - 1 (diminished), - 2 (very diminished).

Fasting blood samples $(10 \mathrm{~mL})$ were taken at the HMPMPS laboratory in an early morning after an overnight fast. Serum samples were analysed for serum total proteins, albumin, globulin, aspartate aminotransferase (AST), alanine aminotransferase (ALT), lactate dehydrogenase (LDH), bilirrubins, creatinine, blood urea nitrogen (BUN), urea, uric acid (Dimension Rx L Max, Dade Behring, USA), hemogram (Advia 120, Bayer Health, USA), fasting plasma glucose [FPG] (Dimension Rx L Max, Dade Behring, USA), erythrocyte sedimentation rate (ESR), creatine phosphokinase (CPK), electrolytes ( $\mathrm{Na}, \mathrm{K}, \mathrm{Ca}, \mathrm{P}, \mathrm{Mg}, \mathrm{Cl}$ ), 
venereal disease research laboratory (VDRL), C-reactive protein (CRP), rheumatoid factor (RF), urine test and cyclic citrullinated antibody test (Ac-antiCCP). All these tests were measured according to standardized procedures recommended by the International Federation of Clinical Chemistry and Laboratory Medicine (IFCC).

The phototherapy lamp developed by our research team (Federal Ministry of Health registration number: 1694E95), uses the electromagnetic spectrum within a range from 425 to $650 \mathrm{~nm}$ (visible light spectrum), 11.33 Joules $/ \mathrm{cm}^{2}$. With the patient in supine position, after registering vital signs (blood pressure, heart rate, respiratory rate and temperature), weight, height and capillary glucose determination, we proceeded to place the phototherapy device $30 \mathrm{~cm}$ above the chest.

The phototherapy scheme was: a) 45 minute daily sessions from Monday to Friday for 2 to 3 months, b) 3 sessions per week of 45 min for 1 to 2 months, c) Twice a week sessions of 45 min for 1 to 2 months, d) A weekly session for $1-2$ months until completion. Weekly frequency and progressive reduction of the phototherapy sessions were determined according to the patients' own improvement.

The protocol was approved by the Research Committee of the HMPMPS (November 2010). We followed the Helsinki Declaration, Fortaleza, Brazil and all patients were asked to sign the written informed consent.

Statistical analysis was performed using SPSS version 19. First, descriptive analyses were performed and then we compared if the group presented differences through the time by Wilcoxon test. Difference was considered significant at $p \leq 0.05$. 


\section{RESULTS}

A total of seven patients, all women, media age of 44 years (range 21-56), with RA were enrolled for this study. Four patients were already in treatment with a Rheumatologist, and three were naïve to any kind of treatment.

The media of antirheumatic drugs that patients were taking at the moment of starting the protocol was of 2.2. The media of time within the protocol was of $140 \pm 7.7$ (SE) days and the media of prescribed phototherapy sessions was of 66 [range 34-77] (Table 1).

Table 1. General characteristics of the patients

\begin{tabular}{|c|c|c|c|c|c|c|c|}
\hline \multirow[t]{2}{*}{ Variable } & \multicolumn{7}{|c|}{ Patient } \\
\hline & 1 & 2 & 3 & 4 & 5 & 6 & 7 \\
\hline Age (years) & 21 & 49 & 41 & 34 & 56 & 46 & 44 \\
\hline Familial cases of RA & 0 & 0 & 0 & 1 & 0 & 0 & 5 \\
\hline State of origin & $\begin{array}{l}\text { State of } \\
\text { Mexico }\end{array}$ & $\begin{array}{l}\text { State of } \\
\text { Mexico }\end{array}$ & $\begin{array}{l}\text { State of } \\
\text { Mexico }\end{array}$ & Guerrero & Hidalgo & $\begin{array}{l}\text { State of } \\
\text { Mexico }\end{array}$ & $\begin{array}{l}\text { Mexico } \\
\text { City }\end{array}$ \\
\hline Occupation & Student & Worker & Worker & Dentist & Home & Home & Worker \\
\hline $\begin{array}{l}\text { Disease duration } \\
\text { (months) }\end{array}$ & 4 & 56 & 43 & 80 & 73 & 39 & 116 \\
\hline $\begin{array}{l}\text { Drugs at the } \\
\text { beginning }\end{array}$ & $\begin{array}{c}\mathrm{Dc} \\
\mathrm{Cl} \\
\mathrm{Mtx} \\
\mathrm{Sz}\end{array}$ & Dc & $\begin{array}{c}\mathrm{Cl} \\
\text { Dc } \\
\text { Pred } \\
\text { Mtx } \\
\text { Pc }\end{array}$ & $\begin{array}{l}\text { Dc } \\
\text { Hcq } \\
\text { Mtx } \\
\text { Pc }\end{array}$ & $\begin{array}{c}\mathrm{Pc} \\
\mathrm{RtD}\end{array}$ & Dc & $\begin{array}{c}\mathrm{Cl} \\
\mathrm{Mtx} \\
\mathrm{Pxc} \\
\mathrm{Sz}\end{array}$ \\
\hline Co-morbidities & & $\begin{array}{c}\text { Obesity } \\
\text { HT }\end{array}$ & & & & $\begin{array}{c}\text { Sjogren } \\
\text { syndrome } \\
\text { HT } \\
\text { HC }\end{array}$ & \\
\hline
\end{tabular}


The clinical characteristics of the studied women are showed in Table 2.

Table 2. Anthropometric and clinical characteristics

\begin{tabular}{|c|c|c|c|}
\hline Variable & Initial & Final & $p$ \\
\hline Spontaneous pain & $6 \pm 2.9$ & $0 \pm 0.14$ & 0.028 \\
\hline Movement pain & $25 \pm 4.3$ & 0 & 0.018 \\
\hline Pressure pain & $32 \pm 4.8$ & $0 \pm 0.72$ & 0.018 \\
\hline Inflammation & $4 \pm 1.6$ & $0 \pm 0.56$ & 0.028 \\
\hline Affected joints & $35 \pm 1.6$ & $0 \pm 1.5$ & 0.018 \\
\hline Deformed joints & $0 \pm 1.5$ & $0 \pm 1.5$ & \\
\hline Functional limitation & $10 \pm 1.9$ & $0 \pm 0.14$ & 0.018 \\
\hline $\mathrm{CRP}(\mathrm{mg} / \mathrm{L})$ & $80 \pm 19.5$ & $0 \pm 29.5$ & 0.042 \\
\hline $\operatorname{ESR}(\mathrm{mm} / \mathrm{min})$ & $40 \pm 6$ & $26 \pm 3.9$ & 0.018 \\
\hline RF (IU) & $80 \pm 172$ & $0 \pm 29.5$ & \\
\hline Total proteins (mg/dL) & $7.8 \pm 0.23$ & $7.6 \pm 0.25$ & \\
\hline Albumin (mg/dL) & $3.7 \pm 0.13$ & $3.9 \pm 0$ & 0.018 \\
\hline Globulins (mg/dL) & $4 \pm 0.27$ & $3.6 \pm 0.23$ & \\
\hline Cholesterol (mg/dL) & $188 \pm 11$ & $177 \pm 13$ & 0.018 \\
\hline Triglycerides (mg/dL) & $104 \pm 15$ & $108 \pm 6$ & \\
\hline
\end{tabular}

CRP: C reactive protein, ESR: erythrocyte sedimentation rate, RF: rheumatoid factor. 
Table 3 shows the results of the evaluated scales.

Table 3. Scales of evaluation

\begin{tabular}{lccc}
\hline \multicolumn{1}{c}{ Scale } & Initial & Final & $\boldsymbol{p}$ \\
\hline Karnofsky & $50 \pm 4.7$ & $90 \pm 2.6$ & 0.018 \\
QOL-RA & $12 \pm 2.6$ & $77 \pm 1.8$ & 0.028 \\
RaQol & $29 \pm 0.75$ & $0 \pm 1.1$ & 0.018 \\
Steinbrocker functional classification & $3 \pm 0.21$ & $1 \pm 0.14$ & 0.017 \\
VAS & $9 \pm 0.6$ & $0 \pm 0.4$ & 0.018 \\
\hline
\end{tabular}

QOL-RA: quality of life-rheumatoid arthritis scale, RAQoL: rheumatoid arthritis-specific quality of life, VAS: visual analogue scale.

All the median scores were significantly better rated after the treatment period. Karnofsky changed from requiring frequent medical care to being capable of normal activity with few symptoms or signs of disease. The RaQol questionnaire decreased abruptly from 29 to cero points. Steinbrocker Functional Capacity Rating changed from limited to little or none of the duties of usual occupation or self-care to complete ability to carry out all the usual duties without handicaps. The pain was remitted after the treatment period.

The acute inflammation variables declined notoriously after the indicated sessions. Erythrocyte sedimentation rate diminished more significantly than CRP although both reached a statistical difference. Metabolically speaking, albumin increased and cholesterol decreased after the survey. 


\section{DISCUSSION}

There are many research lines searching for a better prognosis in RA. In spite of the great advances with the biological drugs, there is not still a cure and the cost of such therapy is not easily affordable for most of the patients. In this line of explorative options, there is scarce information related to the RA treatment with light exposure. In this respect, the described techniques are extracorporeal photochemotherapy (EPC), photodynamic therapy (PDT), photopheresis and UVA.

Extracorporeal photochemotherapy has been applied in refractory RA with clinical improvement, a decline in CRP and no adverse reactions recorded (11). Photodynamic therapy is based on the use of light-sensitive molecules called photosensitizers. This photoactivation causes the formation of singlet oxygen, which produces peroxidative reactions that can cause cell damage and death (12).

The use of photosensitizers is not a new topic in medicine (13). Experimentally, incubation with chloroquine or methotrexate and subsequent laser irradiation at a wavelength of $351 \mathrm{~nm}$ resulted in an at least twenty-fold enhanced cytotoxicity. Both substances therefore may serve for a photodynamic therapy of rheumatoid arthritis (14). We can not exclude the possibility of some patients being beneficiated under a photodynamic effect of either of both drugs.

Ultraviolet light may be effective in the treatment of patients with RA, but elucidation of its precise role requires further study including double-blind trials (15). Photopheresis is an extracorporeal form of photochemotherapy with 8-methoxypsoralen (8-MOP) and UVA radiation. This therapeutic option leads to the induction of antigen-specific immune suppression directed to the pathogenic clone of T-cells (16). In 1991, Malawista et al conducted a study in seven patients with RA who were treated with extracorporeal photopheresis. After a treatment 
period between 12 and 16 weeks positive responses were obtained in four of seven patients, noting a decrease in number and degree of joint involvement and in morning stiffness and pain (17).

Our approach differs in many senses in relation to the above mentioned works. First, we used visible wavelength, which, to our knowledge is the first study demonstrating a clinical benefit in RA. In evaluating the clinical benefits with any treatment in RA patients the use of functional scales is mandatory. Our group has evaluated not one but five scales, all of them with evident demonstration of the successful in managing RA patients with phototherapy.

As it is well known, an objective way to probe the benefit of any treatment is the decreased in inflammatory variables. Our results showed a decrease in CRP and ESR. As an initial attempt we did not quantify TNF- $\alpha$ expression that has been included in a new protocol that has already begun.

A critical point to be considered is the role of vitamin D as its shortage in the diet added to a low sun light exposure could predispose to several diseases including RA (18). In this respect, the fact that we use the 425 to $650 \mathrm{~nm}$ wavelength, could stimulate the vitamin $\mathrm{D}$ synthesis and as a consequence get a clinical benefit derived from this vitamin pathway. Whether phototherapy induces a clinical improvement by reducing oxidative stress, changing isomerization or any other molecular effect was beyond the scope of the present study.

This study has its limitations. The low number of cases does not give us enough power to extrapolate the results to a more diverse population. Also, it was not a randomized clinical trial as it was impossible to enroll enough naïve RA patients and successfully integrate comparative groups. This last attempt has to be developed in a Hospital with considerable RA incidence. 
Despite the above mentioned limitation, our study has a strong point in reporting the results of five clinical scales and not only one.

Another point to be considered is the placebo effect. Without any doubt, this effect contributes to a feel of welfare but it would not be as definitely as has been documented using five different clinical scales. Moreover the placebo effect is conditioned by the personality (19), being extremely difficult that the seven patients had the same factors influencing placebo response. Finally, the mechanism that underlies the phototherapy has yet to be elucidated although there has been documentation of isomer changes and immunosuppression with this technique.

\section{ACKNOWLEDGEMENTS}

Authors thank María Elda Albíter Aguirre, Gabriela Sandoval Platas and Rurik Francisco Calderón Pulido for their collaboration in testing primers and for the initial development of the data base. 


\section{REFERENCES}

1. McInnes IB, Schett G. The pathogenesis of rheumatoid arthritis. N Engl J Med 2011; 365: 2205-19.

2. Blume SW, Fox KM, Joseph G, Chuang CC, Thomas J, Gandra SR. Tumor necrosis factor-blocker dose escalation in rheumatoid arthritis patients in a pharmacy benefit management setting. Adv Ther 2013; 30: 517-27.

3. Saag KG, Teng GG, Patkar NM, Anuntiyo J, Finney C, Curtis JR et al. American College of Rheumatology 2008 recommendations for the use of nonbiologic and biologic diseasemodifying antirheumatic drugs in rheumatoid arthritis. Arthritis Rheum 2008; 59: 762-84.

4. Rindfleisch JA, Muller D. Diagnosis and management of rheumatoid arthritis. Am Fam Physician 2005; 72: 1037-47.

5. Singh JA, Furst DE, Bharat A, Curtis JR, Kavanaugh AF, Kremer JM et al. 2012 update of the 2008 American College of Rheumatology recommendations for the use of diseasemodifying antirheumatic drugs and biologic agents in the treatment of rheumatoid arthritis. Arthritis Care Res (Hoboken) 2012; 64: 625-39.

6. Maverakis E, Miyamura Y, Bowen MP, Correa G, Ono Y, Goodarzi H. Light, including ultraviolet. J Autoimmun 2010; 34: J247-57.

7. Dandie GW, Clydesdale GJ, Jacobs I, Muller HK. Effects of UV on the migration and function of epidermal antigen presenting cells. Mutat Res 1998; 422: 147-54.

8. Vink AA, Strickland FM, Bucana C, Cox PA, Roza L, Yarosh DB et al. Localization of DNA damage and its role in altered antigen-presenting cell function in ultravioletirradiated mice. J Exp Med 1996; 183: 1491-500. 
9. Aberer W, Schuler G, Stingl G, Hönigsmann H, Wolff K. Ultraviolet light depletes surface markers of Langerhans cells. J Invest Dermatol 1981; 76: 202-10.

10. Aletaha D, Neogi T, Silman AJ, Funovits J, Felson DT, Bingham CO 3rd, Birnbaum NS et al. 2010 Rheumatoid arthritis classification criteria: an American College of Rheumatology/European League Against Rheumatism collaborative initiative. Arthritis Rheum 2010; 62: 2569-81.

11. Hilliquin P, Andreu G, Heshmati F, Menkès CJ. [Treatment of refractory rheumatoid polyarthritis by extracorporeal photochemotherapy]. Rev Rhum Ed Fr 1993; 60: 125-30.

12. Holbrook MR, Powell RJ. Is there a future for extracorporeal photochemotherapy in the treatment of the rheumatological diseases? Ann Rheum Dis 1997; 56: 339-40.

13. Levy JG. Photosensitizers in photodynamic therapy. Semin Oncol 1994; 21(6 Suppl 15): $4-10$.

14. Hendrich C, Siebert WE. Photodynamic therapy for rheumatoid arthritis? Lasers Surg Med 1997; 21: 359-64.

15. McGrath H Jr, Smith JL, Bak E, Michalski JP. Ultraviolet-A light in the treatment of rheumatoid arthritis. Clin Exp Rheumatol 1987; 5: 323-8.

16. van Iperen HP, Beijersbergen van Henegouwen GM. Clinical and mechanistic aspects of photopheresis. J Photochem Photobiol B 1997; 39: 99-109.

17. Malawista SE, Trock DH, Edelson RL. Treatment of rheumatoid arthritis by extracorporeal photochemotherapy. A pilot study. Arthritis Rheum 1991; 34: 646-54.

18. Holick MF. Sunlight and vitamin D for bone health and prevention of autoimmune diseases, cancers, and cardiovascular disease. Am J Clin Nutr 2004; 80 (6 Suppl):1678S$88 \mathrm{~S}$. 
Phototherapy in Rheumatoid Arthritis

19. Jakšić N, Aukst-Margetić B, Jakovljević M. Does personality play a relevant role in the placebo effect? Psychiatr Danub 2013; 25: 17-23. 